\title{
FEM Based Prototype of Moving-Coil Coreless Linear-Generator (MCCLG) for Wave Energy Extraction
}

\author{
Raed Althomali ${ }^{1}$ and Mohammed Alsumiri ${ }^{1}$ \\ ${ }^{1}$ Electrical and Electronics Engineering Department, Yanbu Industrial College, Yanbu, Saudi Arabia.
}

\begin{abstract}
Linear generators are one of the most efficient sea wave's energy extraction setup. In the linear generator setup the energy is taken out by the vertical movement of waves. In most of the energy conversion systems, the energy is extracted by rotating motion by using the rotary generators. This paper is based on the prototype design of moving coil linear generator. The analysis of the prototype is done using the Maxwell finite element software. Finite-Element-Method (FEM) is used to analytically calculate the induced voltage and cogging forces. In this research, the FEM model of a coreless moving coil P.M linear generator has been outlined with an air cored stator. The main aim of the prototype is to convert marine energy directly without conversion from one form of motion to another, in regions the wave height is around $50 \mathrm{~cm}$. A detail machine design formula is derived for the bases of initial prototype design. Prototype is modelled using Maxwell 2D FEM analysis. Hardware setup results were discussed to confirm the design, and to explore the working of the prototype as a generator. The movement of coils is accomplished by buoyancy mechanism of sea waves. The EMF generated is $6 \mathrm{Vp}-\mathrm{p}$ according to finite element simulation software. The prototype is able to generate EMF of about $2.5 \mathrm{Vp}-\mathrm{p}$.
\end{abstract}

\section{Introduction}

In the recent decades the exhaustion of fossil fuels and rise of concerns regarding the changes in global weather and the increase level of carbon gases in atmosphere, leading cause to focus on renewable energy sources for electricity. The importance of research in the field of renewable energy is increasing day by day. At the present, the need for renewable power generation has increased dramatically. Two of the most focused renewable energy resources are Solar and Wind energies. While the sea wave energy is side lined, although it is actually one of the most concentrated and constant energy sources [1]. It is estimated that the world wide wave energy reserve is about 140-750 TWh/year keeping in mind the existing wave energy technologies that are developed. There are numerous topologies of wave energy converter (WEC) concepts [2], [3]. Previously several prototypes were presented to convert the oceans energy to generate electricity. They can be summarized as the followings [4]

1) Wave energy converters capture the vertical movement of ocean waves and with help of generators transforms the motion into electricity. This system consists of water-column or buoy mechanism to captures the motion of sea wave in some types it uses sub surface buoy systems [5].

2) Tidal Energy systems converts the energy of sea waves and tides under the surface and transform them into electrical energy. These systems are also known as underwater turbines, wither horizontal or vertical. These rotate with sea wave these are like under water wind mills [6].

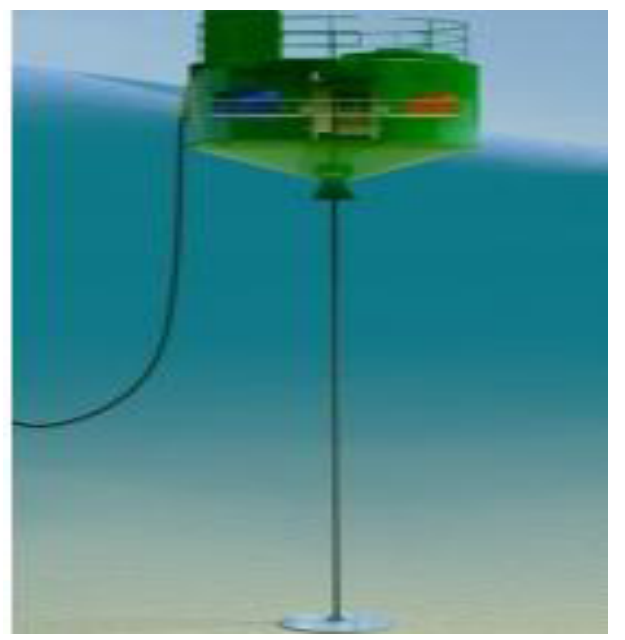

Fig. 1. Wave Energy Converters [5].

3) Ocean temperature difference energy technology is based on the phenomena that there is density difference between the warmer water of sea and colder water. The systems generate electricity through the temperature differential between surface water and deep water. This system is a type thermal generator. 


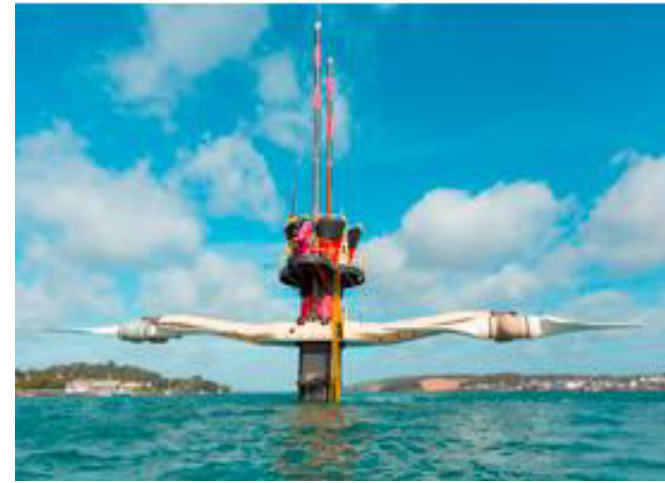

Fig. 2. Tidal/Current Systems [6].

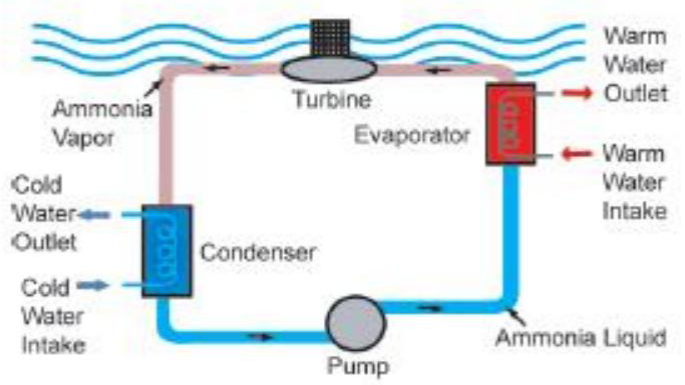

Fig. 3. Ocean Thermal Energy System [7].

4) Marine biomass system uses under water algae which are producing fuels in the shape of gases or liquids. These marine bio fuels are used for electrical energy generation. The earth surface is covered by $70 \%$ oceans. The ocean surface can be used for solar farms as an alternative for on land farms.

There is large number of devices used to convert the wave energy, but many of these devices are in immature or at the stage needs more improvement to able to compete with existing energy conversion devices. There are few devices been tested at large scale and deployed in the oceans. The LIMPET Land Installed Marine Power Energy Transmitter oscillating water column (OWC), is installed at Islay, Scotland, in 2000 a connected to grid able to produce $250 \mathrm{KW}$. In September 2008, other commercial wave energy conversion setup was installed and operating in Northern Portugal [9].

Wave energy conversion system has advantages over the other sources. These advantages are highlighted as below:

1) The energy density of water waves is higher among renewable energy sources [11], [12]. It is well known that sea-waves are results of movement of wind. The wind flow due to change in temperature which is produces by solar energy. This energy strength is of typically 0.1 to 0.3 $\mathrm{kW} / \mathrm{m} 2$ along the horizon is able to produce the winds flow power up-to the strength of 2 to 3 $\mathrm{kW} / \mathrm{m} 2$.
2) The bad effects on the environmental by using wave energy are minimized. It has been noted that the devices which is offshore have the lowest negative effects.

3) In moderate climate, there is a correlation between the due to seasons and the requirement of electrical energy. This is very clear from the report that sea wave conversion can operate and generate electricity up to $90 \%$ of the time. In the comparison of the wind and solar power devices which is up-to 20 to $30 \%$ [12].

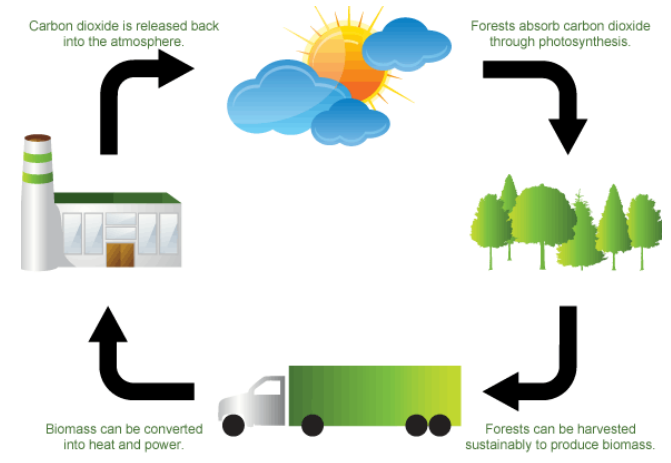

Fig. 4. Marine Biomass [8].

In this research, the performance and FEM model of a prototype coreless moving coil permanent magnet linear generator machine has been outlined with a nonmagnetic stator. The main aim of the prototype is to convert marine energy directly without conversion from one form of motion to another, in regions the wave height is around 50 $\mathrm{cm}$. Detail machine design formula is derived for the bases of initial prototype design. Prototype is modeled using Maxwell 2D FEM analysis. Hardware setup results were discussed to confirm the design, and to explore the working of the prototype as a generator. The movement of coils is performed by buoyancy mechanism of the sea waves. Linear Generators are used to convert the linear motion directly into electromotive force (EMF). In conversion from linear to rotational tremendous amount of energy is lost and hence the conversion efficiency of rotary is less as compared to linear generator. In this project the permanent magnet arranged as stationary and coil is moved through the magnetic field which generates EMF. The EMF generated is $6 \mathrm{Vp}-\mathrm{p}$ according to finite element simulation software. Project concludes with some suggestions for future developments

\section{Linear generator}

Permanent Magnet Linear generator comprises of a magnets and coils. The portion which is subjected to the movement is called as translator. The portion that is not moving is called as stator. These machines can be categorized based on the construction, magnetic field arrangement, and magnets arrangements. In this paper the linear generators are categorized according to its construction. There are three categories of linear generators i.e. Moving-Coil-Linear-Generators (MCLM), 
Moving-Iron-Linear-Generators (MILG) and MovingMagnet-Linear-Generators (MMLG). MCLG are the machines in which the coil is moving with respect to magnets. MILG are the machines in which the flux lines path is changed by changing the reluctance of the path. The change in reluctance of the magnetic path is provided by moving the low reluctance magnetic iron. MMLG are the machines in which the magnets are moving while the coils are stationary. In case of alternator the translator is reciprocated with the help of mechanical force. Permanent Magnet (PM) flux lines cuts the stator coil and voltage is generated in stator. The current is injected into the stator coils of linear motor the field is generated by the current. The field due PM and due to stator coil interact with one another and exert force on translator. Drawbacks in this system is that it has low power factor and the magnet is expose to thermal and impact energy which causes demagnetization of the magnet [13].

\section{Types of linear generator}

\subsection{Permanent magnet linear generator (MMLG)}

These machines are very desirable for most of the application now days having benefits over the other types of linear MMLG have advantages such as high power density, and strength of field. MMLG category there are lot of variation and can be design by numerous methods. To understand this configuration a simplified MMLG is presented in Fig. 5.

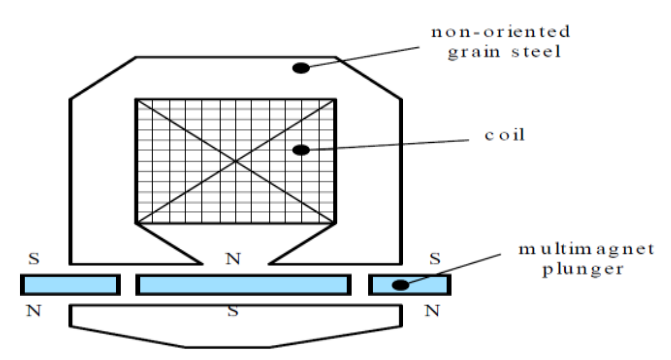

Fig. 5. A Cross Sectional View Of A MMLG [9], [10].

The MMLG presented is designed as cylindrical. The MMLG consists of a coil wound in a stator slot. The ferromagnetic stator has a small gap at the center. In that gap a ring shaped magnets are installed. These magnets are free to move horizontally with the external forces. The move in the air-gap backward and forward induces EMF due to changes of flux linkage with coils in the stator. However, the MMLG have some limitations. One of the crucial one is the structure of high strength magnets are fragile in structure. The structure strength of the magnet material may reduce because of the highspeed fatigue forced by high speed switching of translator. The magnetic properties of magnets decrease when exposed to high temperature. The removal of heat is also issue with this type of machines as the magnets are closed in the stator. The only way to remove heat is through radial radiation this will cause the loss of efficiency

\subsection{Moving iron linear generator}

This is a new type of linear generator. MILG is having design which is and most of the MMLG limitations are tried to remove. MILG can also have lot of variation in terms of design. The simplified MILG prototype is presented, a as shown in Fig.6.

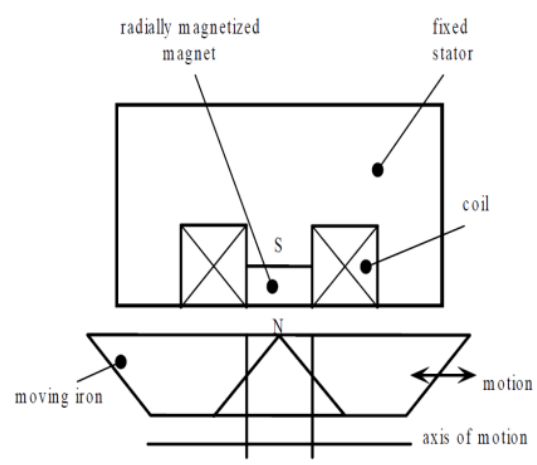

Fig .6. Cross Sectional View Of A MILG [9], [10].

This linear generator consists of iron plunger moving in the cylindrical stator center. The stator is housing the coils and magnets. The magnets are arranged in such fashion that the magnetic flux produced by them should link with stator coils. The iron moves with external forces and it changes the reluctance of the magnetic circuit. This motion causing the change in flux linkage in coils and inducing EMF in these coils.

MILG have some advantages like low cast and rugged design. There are some limitations in MILG for example, the ration of power to weight is less as compared to other machines. The weight of the translator and stator is very high due to which the high-speed oscillation have issues with structure stability.

\subsection{Moving coil linear generator}

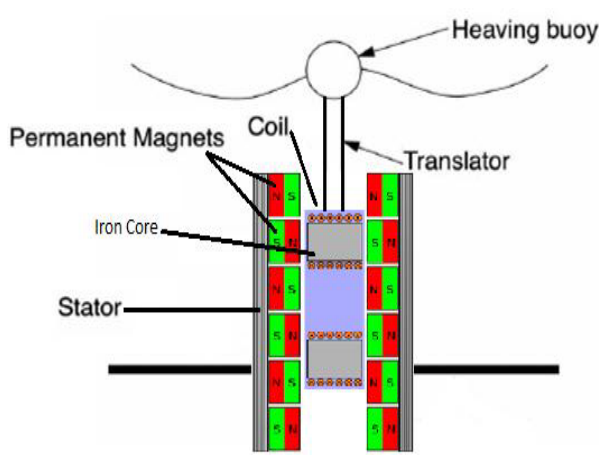

Fig. 7. Moving Coil Iron Linear Generator [9], [10].

Addressing these limitations in MMLG and MILG the type of linear generator is suggested that is, moving coil linear generator (MCLG). MCLG is presented to reduce most of mentioned problems. There are two types of design methodologies; Moving Coil Iron-cored Linear Generator (MCILG) and Moving Coil Coreless Linear Generator (MCCLG). The MCILG methodology is to 
design a translator made from iron. The translator have slots to accommodate the windings. The translator is coupled with oscillating force. The magnets are located on the stationary stator. When the translator coils moves in magnetic field of stator magnets the EMF is induced. The simplified MCILG is shown in Figure 7.

For the iron cored, EMF induced in the MCILG increases with increase in the coil thickness which will increase the thickness of stator. The EMF induced is increased also with number of turns in translator which results the increase in the weight of the translator. The flux linkage with coils decreases due to saturation caused by the stator core thinning. The cogging force for MCILG is very higher and it is one of the limitations of these machines.

The MCCLG is based on the concept of translator having no iron parts to decrease the cogging. The coreless translator winding is coupled with external translational forces. The winding will be magnetically coupled with stator magnets inducing EMF in the coreless coils. The MCCLG design is shown in Figure 8.

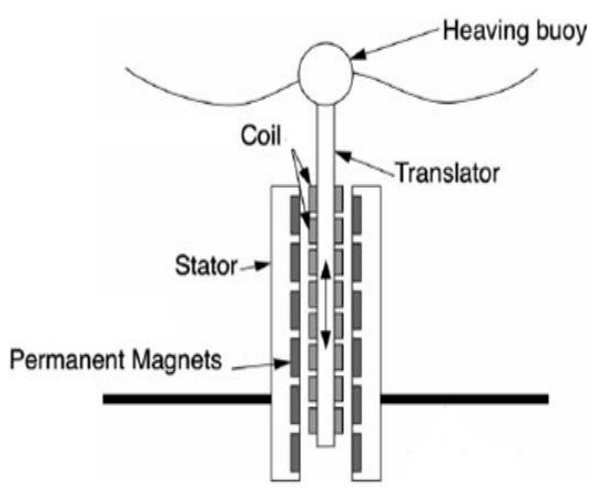

Fig. 8. Moving Coil Coreless Linear Generator (MCCLG) [9], [10].

The Moving Coil Coreless Linear Generator (MCCLG) is presented in the paper. Successively, MCCLG will be considered for use in the wave energy conversion system. The MCCLG is simulated and the operation of the generator is studied. The results from the simulation suggests that MCCLG is a suitable for the field renewable energy conversion system in Saudi Arabia. Much detail about MCCLG will be discussed along with simulations, advantages and drawbacks will be presented in the coming sections of this paper. Also, a detailed model of the MCCLG is presented and explained in Figs. 15 and 16.

Referring to the previous discussion it is clear that MCLG are one of the better then other two types MMLG and MILG. MCLG coils are moving and magnet are placed on stationary stator hence magnets are easily cooled down. The magnets are also not subjected to the higher trust forces due reciprocating forces. Therefore, MCLG's are rugged and easy to design. The maintenance of magnets and other magnetic parts are easy and easy to install. These benefits MCLG are more desirable for industrial production. The light weight translator high frequency oscillation can be converted to energy. MCLG can compensate trust forces. The MCLG can achieve higher efficiency and specific power of nearly rotary generator. There are lot of advantages over other types of LG but MCLG have some limitations. The coils on translator requires the connection that can withstand translational motion which arise a problem of connector wear and tear problem in higher power applications.

\section{Design Methodology}

The design is based on data available from Yanbu off shore in which the average yearly wave's height is about 0.5 meters. Eight permanent magnet poles are placed on the stator made of plastic sheets. The coil is connected with a non-magnetic rod i.e. plastic. When the Buoy moves with the rod connected, the coil moves in the field of the magnets and thus produces an EMF with a value of $3 \mathrm{Vp}-\mathrm{p}$ and $6 \mathrm{Vp}-\mathrm{p}$ (simulated). The experiments, that were done, provide useful data for this design. This methodology will be applied using prototype design and tests to prove the theory of this type of machine. In addition, finite element simulations (FE) are implemented to obtain an FEM model of MCLG. Finite element software used is ANSOFT Maxwell, which is widely used in engineering designs of electromagnetic and electromechanical devices. Figure 9 shows experimental setup and arrangements of magnets.

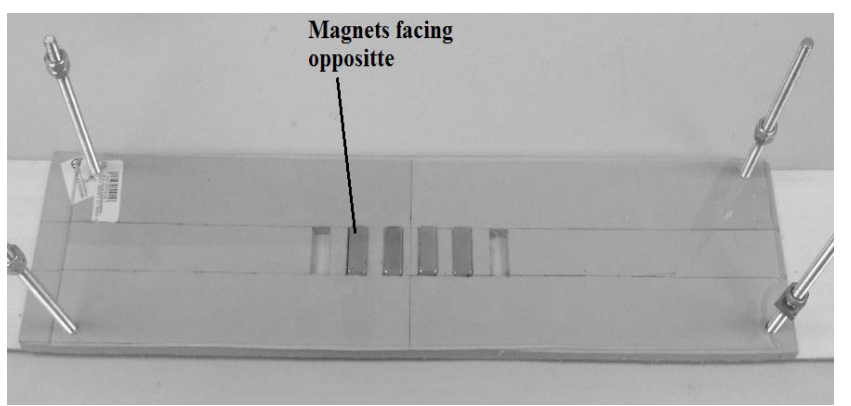

Fig. 9. Magnet Arrangements MILG and MCCLG.

\section{Finite Element Method (FEM)}

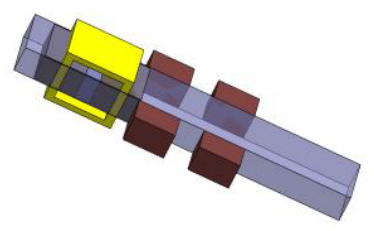

Fig. 10. 3D Design of moving Coil Linear Generator.

The analytical problem having complex solutions or need some approximation and to get very near solution the Finite Element Analysis (FEA) is used. This analysis is used to solve the problem of science and technology where complicated geometry is geometries are involved. FEM is used to solve the problem of engineering like load calculation and material properties calculations. Nowadays, Design geometry which is a commonly used method for multi physics problems is more complicated and the accurate solutions are desirable. In this paper The MCCLG and MCILG are setup in FEM. For MCILG the space between the coils is given properties as Iron and for 
MCCLG the central area of coil got the properties of free space as shown in fig. 10 .

\section{Prototype results}

The In the start of process of prototype implementation, experimental results were low and not up to the expected level. A revision to the design calculation conducted with improvement on air gap of the machine and number of turns of the coil resulted in better outcomes as shown in Figure 11. Output voltage reached $4 \mathrm{Vp}-\mathrm{p}$, which is still not up to the expected level. Some limitations such as; materials availability in local markets and limited local manufacturing facilities. Design is one of the limitations as it is approved in FEM analysis.

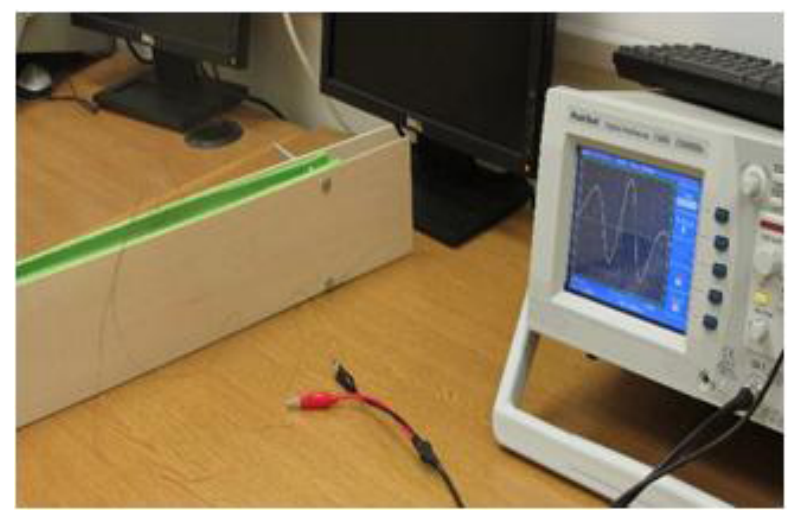

Fig .11. Prototype Result on Oscilloscope.

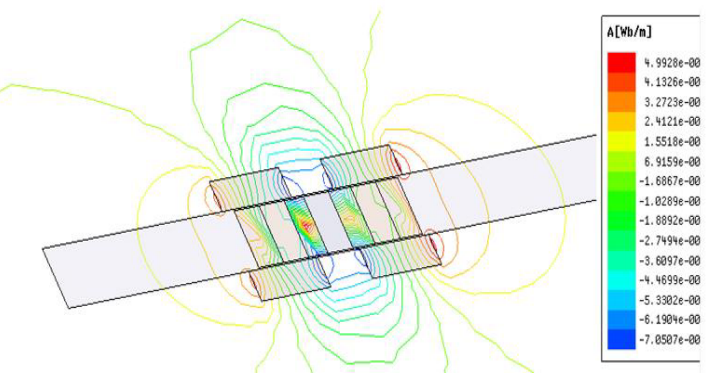

Fig. 12. MCILG Flux Lines.

Finite element method showed more promising results and provided wider vision to the project. Moreover, allowed the investigation of the deficiencies of the prototype model. The results of MCILG and MCCLG are given in figures list below.

From all aspects comparison conducted on Iron-core and Coreless Linear Generators. The comparison showed that both are usable for our needs with the following differences; Voltage and current are induced in both machines, but MCILG has higher values, Flux produced using MCCLG has lower values of flux line concentration and density than MCILG. For cogging force on the translator MCCLG for sure is in better condition than MCILG due to the elimination of ferromagnetic materials in the translator construction. However, both machines are applicable solutions for use.
On the other hand, Moving Coil Coreless Linear Generator machine has been selected for its design simplicity and lighter weight.

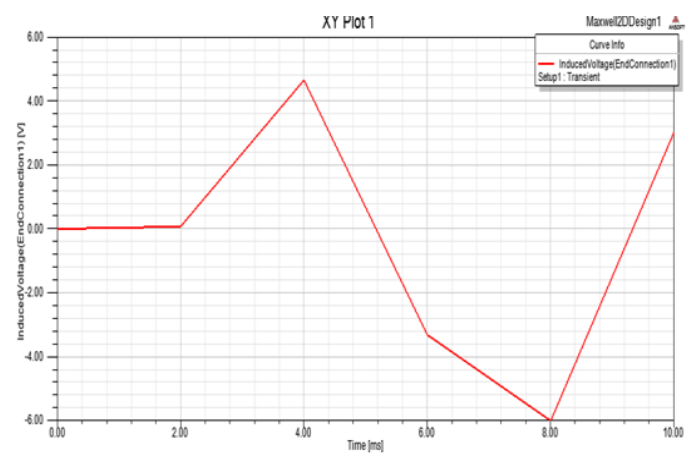

Fig. 13. MCILG Voltage Induced.

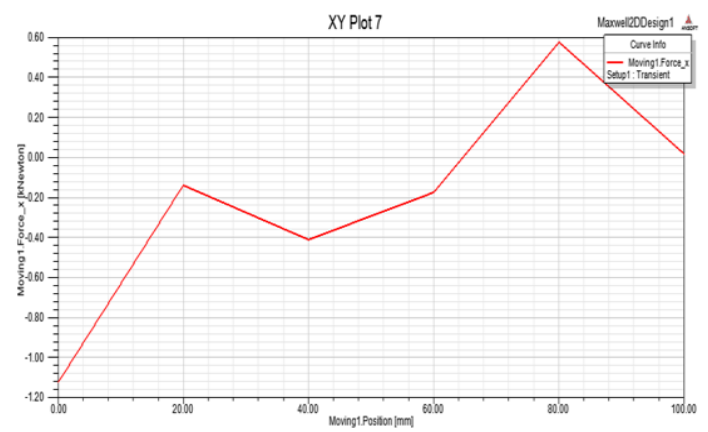

Fig. 14. MCILG Cogging Force.

\section{Conclusion}

This paper is focused on design and study the performance of a linear generator. The design analysis and simulation of Moving Coil Coreless Linear Generator MCCLG is presented in the paper. The study is focused to methodology to increase efficiency and power to weight ratio Machine air gap flux and cogging forces simulation is done by FEM analysis. The FEM software package is used to simulate MCCLG. The output voltage of generator is obtained by performing machine simulation. The output of generator is analyzed by FEM. The design parameters are calculated by the data locally and prototype is designed and tested. The fabrication of prototype by local market was a challenging.

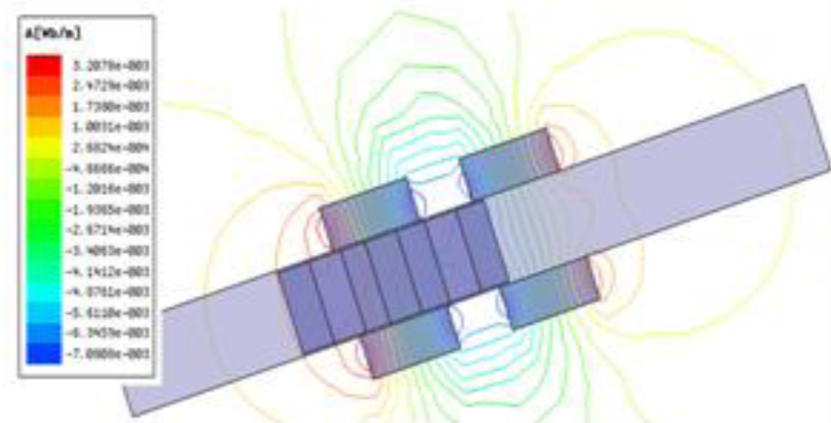

Fig. 15. MCCLG Flux Lines. 


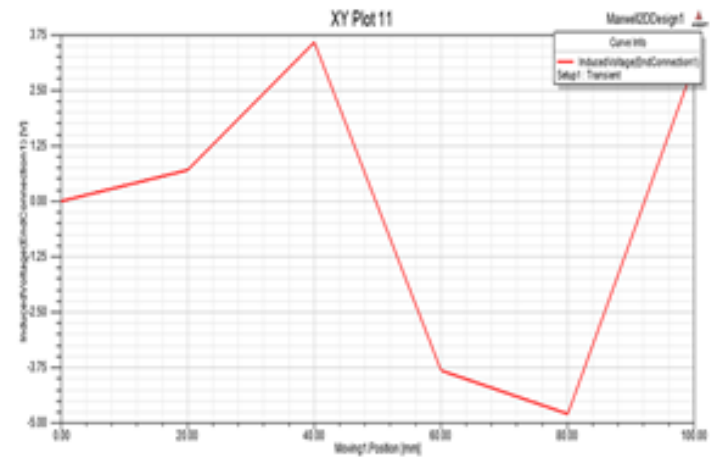

Fig. 16. MCCLG Voltage Induced.

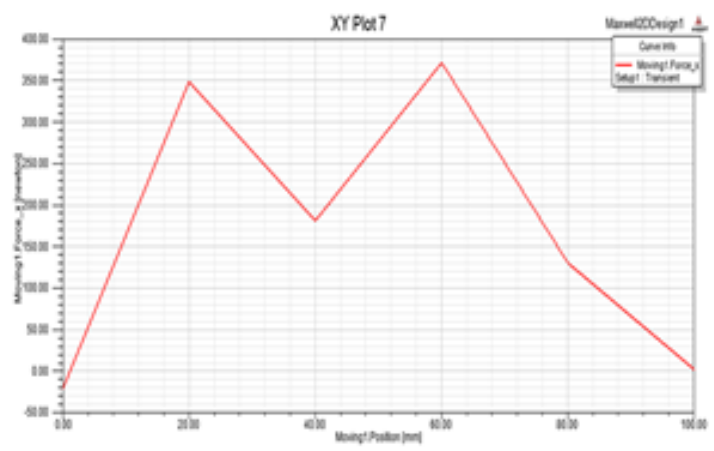

Fig. 17. MCILG Cogging Force.

\section{References}

1. Muhammad Rifa'I., Frasisco Danang.,Sarjiya. "Design and analysis of tri core permanent magnet linear generator for wave energy conversion in south coast of Java Island", 6th International Annual Engineering Seminar, InAES 2016, DOI: 10.1109/INAES.2016.7821944.

2. U.S. Department of the Interior "Technology White Paper on Wave Energy Potential on the U.S. Outer Continental Shelf," 2006. URL:

3. ww.ocsenergy.anl.gov/documents/docs/OCS_EIS_W hitePaper_Wave

4. Dulpichet Rerkpreedapong"Field Analysis and Design of a Moving Iron Linear Alternator for Use with Linear Engine"Master Thesis, College of
Engineering and Minerals, West Virginia University 1999.

5. Loránd SZABÓ, Claudiu OPREA "FEM BASED ANALYSIS OF ADVANCED LINEAR GENERATORS FOR WAVE POWER PLANTS"MicroCAD 2007:International Scientific Conference, 22-23 March 2007

6. Kristof., Guillaume UGent, Bart Meersman et. al. , "A power take-off and control strategy in a test wave energy converter for a moderate wave climate "Proceedings of the International Conference on Renewable Energies and Power Quality (ICREPQ'16). 2016.

7. Siemens New Archives "Hat trick for SeaGen tidal current turbine" http://www.siemens.co.uk/en/news_press/index/news _archive/seagen-tidal-currant-turbine-milestone-hattrick.htm 2017, http://hal.archives-ouvertes.fr

8. Thermal-Fluids Central "Ocean Thermal Energy Conversion" https://thermalfluidscentral.org/encyclopedia/index.p $\mathrm{hp} /$ Ocean_Thermal_Energy_Conversion access date 2018

9. Williams renewables "Biomass" http:/www.williamsrenewables.co.uk/biomass/ (access date at 2018)

10. Thorpe, T. W. A brief review of wave energy, Technical report no. R120, Energy Technology Support Unit (ETSU), A report produced for the UK Department of Trade and Industry, 1999.

11. Fazal, Imran, Mohd Noh Karsiti, K.S. Rama Rao, and Saiful Azrin Zulkifli. "Modeling and Simulation of Moving Iron Linear Generator (MILG)", Applied Mechanics and Materials, 2011

12. Johannes Falnes. "A review of wave-energy extraction". Marine. Structure, Elsevier 2007, 185201.

13. Pelc, R. and Fujita, R. M. "Renewable energy from the ocean." Marine. Policy, Elsevier 2002, 26(6), 471-479.

14. Arshad W. M., Bäckström T., Thelin P., and Sadarangani C., "Integrated free-piston generators: An Overview”. IEEE NORPIE-2, Stockholm, 2002. 